\title{
The problem of preparing a teacher for the implementation of the continuity of education of students in primary and secondary schools
}

\author{
A.K. Mendygalieva ${ }^{1 *}, N . V$. Litvinenko ${ }^{2}$, and N.T. Nikolaeva ${ }^{3}$ \\ ${ }^{1}$ Orenburg State Pedagogical University, Orenburg, Russia \\ ${ }^{2}$ Orenburg State Pedagogical University, Orenburg, Russia \\ ${ }^{3}$ Orenburg State Pedagogical University, Orenburg, Russia
}

\begin{abstract}
Russia's integration into the global innovation sphere, characterized by the emergence of an information society, the transition to an economy based on knowledge, the value of human capital, has determined a new vector for the development of general education. It is faced with the strategic task of updating the content, teaching methods and achieving on this basis a new quality of education in the context of maintaining its fundamental nature and at the same time meeting the modern and innovative needs of society, the state and the individual. The solution to this problem is facilitated by the comprehension and implementation of new approaches to the continuity between primary and secondary schools, which ensure the recognition of their complementary, partner coexistence in the context of strategic lines of interconnection, coordination and complementarity of goals, updated content, organization and technologies of advanced education for the optimal formation of personal, meta-subject and subject results of students in the implementation of Federal State Educational Standard of Primary General Education and Federal State Educational Standard of Basic General Education. The article proposes one of the ways to solve this problem - to increase the professional competence of teachers of primary general education and teachers of mathematics of basic school in the field of implementing the continuity of mathematical education. The solution to the stated problem is impossible without special training of teachers of primary and secondary schools, which ensures the formation of readiness to implement the continuity of mathematical education of students in primary and secondary schools in the unity of motivational, technological and reflective components.
\end{abstract}

\section{A problem statement}

Background. Ensuring continuity at various levels of general education that meets the requirements of the country's current social development is one of the primary tasks. The

\footnotetext{
* Corresponding author: ipcs-profped@yandex.ru
} 
regulatory framework for solving this problem consists of: Federal Law "On Education in the Russian Federation"; State program of the Russian Federation "Development of education for 2013-2020"; Federal target program for the development of education for 2016-2020; National educational initiative "Our New School"; Concept of Mathematical Education in the Russian Federation (2013); Federal State Educational Standard of Primary General Education (FSES PGE); Federal Educational Standard of Basic General Education (FSES BGE).

FSES PGE and FSES BGE define one of the main directions of the continuity of mathematical education at both levels, the readiness of students for self-development, selfeducation. The Federal Law "On Education in the Russian Federation" states that the degree of development of intelligence is a guarantee of a person's personal freedom and independence.

However, according to scientists, signs of mismatch and weakening of continuity at various levels of general education have begun to grow lately [1]. According to TIMSS 2011, 2014 (assessment of the quality of mathematics and science education in primary, secondary and secondary schools in grades 4,8 and 11), primary school in Russia is ranked 6th in the world in terms of mathematics education, and these achievements are being lost in primary school ... The Concept for the Development of Mathematical Education in the Russian Federation indicates that the choice of the content of mathematics education at all levels of education is subject to obsolescence and is formal and divorced from life; continuity between levels of education is broken.

An analysis of the practice of assessing the activities of educational organizations in the aspect of implementing the continuity of mathematical education in primary and secondary schools showed that teachers are forced to choose one of the many educational and methodological complexes, there is a large number of lines of textbooks in the same parallel, reflecting different author's approaches to training. Textbooks do not satisfy teachers with their inconsistency with modern ideas about the goals of school, including mathematical education. The initial stage in schools is built on the basis of a developing concept of teaching $(86.8 \%)$, and the main one is based on the traditional didactic concept $(75.8 \%)$. The construction of the process of mathematical education at school does not sufficiently meet the requirements of age-specificity, practical significance and conformity to the modern level of development of pedagogical theory and practice.

Consequently, at the present stage of the formation of pedagogical science, there is a need to ensure the continuity of individual levels of native mathematical education, not only in terms of subject content, but also in terms of the functional-technological, scientificmethodological and psychological-pedagogical level of organizing the educational activities of students.

In order to ensure the effectiveness of the continuity of students' mathematical education, it is required to design a continuous relationship between the initial and general educational stages as an enduring and transitory in the light of new tasks of the content of the educational process in the context of preserving and value-semantic processing of the mathematical heritage of the past, the introduction of alternative mathematical programs and technologies as a resource for increasing the level of mathematical literacy of students, ensuring the readiness of graduates for continuous education and self-education in various areas of constantly changing social practice. Science has accumulated a sufficient amount of interdisciplinary (socio-philosophical, sociological, pedagogical, socio-psychological, culturological, etc.) scientific knowledge, which makes it possible to substantiate the basis of research. Despite a large number of fundamental and applied research and development, the problem of the continuity of mathematical education of students in the primary and the basic school is not solved with the due measure of effectiveness. The inconsistency of 
approaches to the study of the indicated problem, insufficient coverage of the issue in pedagogy and methodology, inconsistency in the use of teaching materials and textbooks.

Status of a Problem. In recent decades, the description of the characteristics of a teacher who is competent in the implementation of the continuity of education in primary and secondary schools proceeds from the position of native pedagogy: pedagogical activity belongs to the class of transforming and managing at the same time (I.A. Zimnyaya, N.V. Kuzmina, V.A. Slastenin, A.V. Khutorskoy), this, in turn, requires sufficient professionalism or competence.

The professional competence of a teacher in the reference literature is interpreted as "the teacher's possession of the necessary amount of knowledge, skills and abilities that determine the formation of his or her pedagogical activity, pedagogical communication and the teacher's personality as a carrier of certain values, ideals and pedagogical consciousness" [2]. A.K. Markova reveals professional competence through the definition of such characteristics as a combination of mental qualities that allow acting independently and responsibly; ability to assess and measure the final result of activities; irreducibility to human education and others [3].

Professional competence is also understood as a quality that is formed in the educational process, manifested in the design and implementation of activities, taking into account qualification requirements [4].

Researchers call the pedagogical competence of a teacher not only the unity of his theoretical and practical readiness for the implementation of pedagogical activity, but also a certain fusion of their professional experiences and functions [5].

Note that the glossary of second generation standards provides a definition of professional and pedagogical competence, which includes not only a set of knowledge and skills, which are the core of a teacher's competence, but also necessarily significant personal qualities, value orientations of a teacher, i.e. competence is broader than knowledge, abilities and skills and is not their sum [6].

For our study, it is essential to establish a relationship between the concepts of competence and competence, competence and readiness for professional activity. Based on the research of I.A. Zimnyaya, Yu.G. Tatura, V.A. Slastenin, we come to the conclusion that: professional competence has in its composition a complex, an alloy of competencies; the formation of professional competence is carried out through the formation of a complex of competencies; an indicator of professional competence is the level of formation of each component of its competence [7].

According to Yu.G. Tatura, competence is the quality of a specialist who has completed education at a certain level, expressed in the ability on its basis to successfully carry out professional activities, taking into account its social significance [8].

Consequently, the teacher's competence is an indicator of his or her readiness for professional activity. Therefore, in the future, we will proceed from the fact that the purpose of training a specialist is to form his or her readiness to carry out professional activities, which presupposes that a teacher has professional competence, manifested in the presence of a complex of professionally significant competencies [9].

Thus, the teacher's competence in implementing the continuity of education in primary and secondary schools, in our opinion, is represented by general professional, specific, socio-psychological and autopsychological components. They are collectively characterized by competence in the field of solving problems of continuity of primary and basic general education: the presence of fundamental professional basic knowledge, professionally significant personality traits (readiness to quickly adapt to new working conditions, regularity in improving their professional level, the desire to use new technologies, theoretical and methodological readiness in the subject, pedagogical and psychological literacy, cognitive, communicative, informational and organizational skills) [10], the ability 
to take constructive and practice-oriented competent actions in various types of life in general and in the performance of professional duties in particular, possession at a high level of the system-activity approach as the basis continuity in the organization of educational activities of primary and secondary school students.

At the present stage of the development of society and the state, there is sufficient scientific, theoretical and practical experience in the issue of the teacher's readiness for professional activity (V.P. Bespalko, V.M. Monakhov, V.V. Serikov).

Consideration of readiness for professional pedagogical activity led us to the need to clarify this concept in its most general form. Willingness is an agreement to do something; property of the readiness, state of the subject, ready for any activity. It has two sides: external (a consequence of the influence of external organized factors) and internal (the result of the activity of the person himself), which are closely interconnected. V.A. Slastenin defined theoretical readiness as internal, and practical readiness as external [11]. "Theoretical readiness for pedagogical activity is manifested in the generalized competence of the teacher to think or, in another way, in constructive and gnostic skills, which belong to the group of internal (ideal) skills; practical is expressed in external (subject) competences competencies to act pedagogically, which are represented by organizational and communicative skills" [12].

\subsection{The objective of the work}

The analysis of psychological and pedagogical literature showed that the phenomenon of readiness for professional activity is studied at the following levels:

- personal, considering readiness as a manifestation of individual and personal qualities, due to the nature of future activities (B.G. Ananiev, A.N. Leontiev); as a special mental state, an integral manifestation of personality, occupying an intermediate position between mental processes and personality traits (A.K. Makarova); as a synthesis of personality traits that determine its suitability for activity (A.A. Derkach); as a multilevel structure of personal qualities, allowing to carry out certain activities (N.N. Dyachenko) [13];

- functional, representing it as temporary readiness and working capacity, pre-launch activation of mental functions, the ability to mobilize the necessary physical and mental resources for the implementation of activities;

- personality-activity, which determines readiness as an integral manifestation of all aspects of the personality, as an integrative quality, which is a set of interrelated components, and as a result of special training and an active-effective state of the individual (A.A. Derkach, M.I. Dyachenko) [14];

- in the context of a specific type, form or quality of activity, considering the readiness for independent activity, for self-education, for creative activity, for professional activity (M.N. Skatkin) [15].

In the studies of K.M. Durai-Novikova is emphasized that professional readiness is a prerequisite for effective teacher activity, but this is not an innate quality, but the result of special training. Readiness for pedagogical activity is the level of professional skill of a teacher, which includes mastering the standards of vocational pedagogical education [16]. Thus, readiness for pedagogical activity is interpreted broadly: on the one hand, as a personality quality, which includes a positive attitude to the profession, abilities, knowledge, skills, stable professionally important qualities (memory, thinking, etc.); on the other hand, as an actual psychological state, a regulator of pedagogical activity (K.M. Durai-Novikova, V.A. Slastenin).

Based on the analysis of psychological and pedagogical research, our own conclusions drawn on this basis, the author's approaches to determining the essence of the teacher's competence in the implementation of the continuity of education in primary and secondary 
schools, we have identified the following characteristics of the teacher's readiness to implement this process: academic knowledge, professional abilities and skills. This logic of presentation of readiness components is due to the fact that it is knowledge, skills and abilities that constitute the instrumental basis of competencies, and these, in turn, provide competence in this area.

\section{Materials and the results of the research}

Thematic justification. The problem analyzed in this article is of decisive importance for disclosing the risks that negatively affect the continuity of education in primary and secondary schools (an increase in the number of alternative author's programs that are not consistent with each other in the subject content; insufficient methodological developments that take into account continuity in the links of education; not an expedient approach to training students without taking into account the level of their functional literacy; insufficient implementation of end-to-end vertical integration, which determines purposefulness, progressiveness and orderliness, the continuity of personal, metasubject and subject results of students in the implementation of FSES PGE and FSES BGE; inconsistency in the interaction of primary target components, subject content, application of forms, methods and technologies of teaching mathematics; overload of teachers; insufficient skills of students to optimally implement the acquired mathematical knowledge and learning in practical situations) allows us to reveal the problematic field of the prospects for studying the continuity of education at all its levels.

Methods of the Research. To achieve the goals and solve the research problem, the following general scientific methods (analysis, synthesis, comparison, generalization, classification) and specific scientific (questioning, interviewing teachers, pedagogical modeling) were used, which allow to analyze the existing situation, give its pedagogical interpretation and suggest possible ways and solutions within the framework of the leading for this research system-activity approach.

The theoretical and methodological basis of the research was formed by: the theory of universal connection, interdependence and integrity of phenomena; provisions on the unity of personality and activity, consciousness and activity; theory of educational content; philosophical, psychological and pedagogical theories that reveal the general scientific category of "continuity" as a space for strategic design of education at different levels, ensuring its effectiveness in primary and secondary schools, humanistic ideas of selfactualization, self-realization of the individual in the aspect of continuity in primary and secondary schools; culturological, axiological, system-activity and personality-oriented ideas of the formation of students in successive education; provisions on the student as a subject of research at different age levels of development; modern concepts of humanization of education in the process of professional training of a teacher; the idea of continuing education.

The program "Continuity of mathematical education in primary and secondary schools on the basis of a system-active approach in the context of the requirements of the Federal State Educational Standard of the PGE and the Federal State Educational Standard of BGE" is aimed at increasing the professional competence of teachers of primary general education and mathematics teachers of basic schools in the field of implementing the continuity of mathematical education of students in primary and secondary school.

The objectives of the program are:

1. To familiarize teachers of primary grades and teachers of mathematics of basic school with the main approaches to the implementation of the continuity of mathematical education of students in primary and secondary schools, modern trends in the development 
of the subject area "Mathematics" and effective methods and technologies of successive learning.

2. To provide motivational mechanisms for the development of the professional competence of primary school teachers and teachers of mathematics in basic school in the field of implementing the continuity of mathematical education of students in primary and secondary schools.

3. To train teachers of primary grades and teachers of mathematics of the basic school in the design and organization of the implementation of the continuity of mathematical education of students in primary and secondary schools in the context of the implementation of the FSES of the second generation.

The program is targeted at the main category of learners who are primary school teachers and primary school mathematics teachers.

The expected result of the implementation of the program is the teacher's readiness to implement the continuity of the mathematical education of students in primary and secondary schools.

Focusing on the structural components of the content of education, presented in the concept of I.Ya. Lerner, M.N. Skatkin, V.V. Kraevsky, in the professional training program of a teacher for the implementation of the continuity of mathematical education in primary and secondary schools, we single out the target, organizational, activity, content and effective components, taking into account the individual experience of the teacher and their changing content.

The program "Continuity of mathematical education in primary and secondary schools on the basis of a system-activity approach in the context of the requirements of the Federal State Educational Standard of PGE and Federal State Educational Standard of BGE", developed by us, was based on technologies adequate to the competence content.

For this, various forms of cooperation between students and teachers were planned: work in groups, design, mastering techniques of personal communication, dialogue interaction, and collective thought activity. In the content of the sections of the program, the optimal ratio of lecture and practical classes and the work of the trainee site are determined.

Educational work was organized using such forms as: lectures, lectures "visualization", lectures - dialogues, seminars, discussions, workshops, consultations, design in a group, analysis of video lessons, conducting pedagogical and internship sites.

The content component of the teacher training program was built according to the algorithm: "familiarize - study - master - interpret - develop - implement". Let's describe it in more detail.

The maximum activity of teachers is achieved by practice-oriented tasks that are close to their professional interests (examples from practice, previous experience in conducting similar seminars, analogies from other areas); a method of activating attention, based on some controversial statement, contradictory statement (statement against the authoritative opinion of a well-known specialist).

The approbation of the program "Continuity of mathematical education in primary and secondary schools on the basis of a systemic-active approach in the context of the requirements of the Federal State Educational Standards of PGE and Federal State Educational Standards of BGE" gave positive results. The results of a survey of 212 teachers among whom there were primary school teachers (116 people) and mathematics teachers (96 people) indicate a positive dynamics in the formation of teachers' readiness to implement the continuity of mathematical education among students in primary and secondary schools.

The results obtained on the cognitive criterion of the formation of teachers' readiness to implement the continuity of mathematical education of students in primary and secondary schools indicate that knowledge of ways to achieve educational results and methods of 
assessing learning outcomes among teachers at a creative level is $83 \%$, and $92 \%$ of respondents know at the same level educational tasks and generalized methods of activity inherent in the content of education in primary and secondary schools; teachers' knowledge of normative documents, the content of mathematics education is $67 \%$, knowledge of basic teaching methods based on the system-activity approach - 63\%, laws, principles of succession of mathematical education, the model of its implementation in primary and secondary schools - 75\% [17].

The positive dynamics of the teacher's readiness to implement the continuity of education in primary and secondary schools made it possible to conclude about the formation of the cognitive criterion among teachers. This indicator increased, since teachers had the opportunity in the process of mastering the program "Continuity of mathematical education of students in primary and secondary schools on the basis of a system-active approach in the context of the requirements of the Federal State Educational Standard of the PGE and the Federal State Educational Standard of BGE" to get acquainted in more detail with the essence of the problems of organizing and implementing the continuity of mathematical education [18].

The presence of a stable motivation to implement the continuity of education in primary and secondary schools (75\%) - was revealed in the course of the survey (the questionnaire "Motivation of professional activity", "Map of pedagogical assessment and self-assessment of the teacher's ability to innovate" and tracking teachers' qualifications)

It was found that the implementation of the continuity of education in primary and secondary schools was facilitated, in the opinion of the interviewed teachers, by a favorable motivational environment at school (96\%); work on a single course "Mathematics 1-6" $(93 \%)$; the current system of teacher training $(87 \%)$. Of these $73 \%$ of respondents noted that they achieved the best results in their work thanks to participation in the experiment in the course of mastering the program "Continuity of mathematical education in primary and secondary schools on the basis of a system-activity approach in the context of the requirements of the Federal State Educational Standard of PGE and Federal State Educational Standard of BGE."

Analyzing the readiness of teachers to implement the continuity of education in primary and secondary schools in the field of the technological criterion, one can single out the parameters that are mastered at the creative level by a significant majority of teachers (quantitative indicators of 50\% and above): possession and ability to apply in practice pedagogical technologies of successive mathematical education of students in primary and secondary school (respectively $76 \%, 19 \%, 5 \%$ ), the use of constructive and design skills at a high and intermediate level in the implementation of the continuity of mathematical education of students in primary and secondary schools (69\% and 22\%).

Analysis of the dynamics of indicators of the technological criterion of teachers' readiness to implement continuity indicates the positive results of experimental work.

The number of high (creative) indicators according to the technological criterion in the sample of teachers also increased significantly, and the number of low (reproductive) indicators decreased after the experiment. The data obtained indicate that in the course of mastering the program of problem courses "Continuity of mathematical education of students in primary and secondary schools on the basis of a system-activity approach in the context of the requirements of the Federal State Educational Standard of the PGE and the Federal State Educational Standard of BGE" education of students, about ways to solve emerging problems, about pedagogical technologies that make it possible to more successfully organize and implement the process of continuity at these levels, which contributed to the practical application of the acquired skills by teachers at a higher level.

Noteworthy are indicators with high quantitative characteristics (50\% and above), indicating the formation of such reflexive indicators as the degree of awareness of the goals 
and objectives of the activity, the ability to draw up and analyze plans and lesson outlines at a creative and productive level (respectively $86 \%, 14 \%$, and there were no teachers with a low level at all); the ability to analyze problem situations, evaluate the results of activities, to understand the adequacy of professional actions, abilities and skills (respectively, from $20 \%$ to $74 \%$ ). At the same time, $18 \%$ of teachers believe that they are able to analyze a lesson at a productive level, and at a reproductive level - 5\% [19].

The data obtained show that teachers are ready at a creative level for the implementation of the continuity of education in primary and secondary schools in accordance with the requirements of the Federal State Educational Institution of Education of PGE and Federal State Educational Standard of BGE.

Thus, the data obtained indicate the effectiveness of experimental work and the positive dynamics of teachers' readiness to implement the continuity of education in primary and secondary schools, since there is a significant increase in indicators during the transition from reproductive (low) to creative (high) level.

The results of approbation of the program "Continuity of mathematical education in primary and secondary schools on the basis of a system-active approach in the context of the requirements of the Federal State Educational Standard of the PGE and the Federal State Educational Standard of BGE" indicates that the teacher implementing the basic educational program within the framework of the philosophical, cultural, sociological, psychological and pedagogical concepts, the content of the branches of scientific knowledge that form the basis of the subjects taught, and their areas of application in various spheres of human activity; be able to assess the current state, resource and development potential of the student and propose scientifically based methods to improve their effectiveness; take into account the individual characteristics of students in the educational process, implement management functions in their activities, carry out professional reflection, use private methods, analyze programs, educational and methodological complexes and individual didactic materials, develop didactic materials; possess pedagogical, information and communication technologies, professional communication skills, the ability to solve professional problems, etc. At the same time, the teacher's competence in implementing the continuity of education in primary and secondary schools is manifested in the presence of professionally significant personal qualities that are inseparable from the organization of educational activities of students.

\section{Conclusions}

We see the prospect of solving the problem of the continuity of mathematical education in primary and secondary schools in the following:

- in the development of diagnostic tools that have a specific content of the use of integrative assessment, expressed in the conjugation of two parameters: subject-oriented (characterizing the level of educational achievements of students) and procedural (reflecting the teacher's readiness to implement the continuity of education in primary and secondary schools);

- in substantiating the pedagogical conditions (the consistency of the positions of the subjects of education in all conceptual and content-methodological lines of training students; creating an atmosphere of psychological comfort, mutual understanding between the participants in the educational process; pedagogical support of teacher training in the implementation of continuity to the implementation of the continuity of education in primary and secondary schools);

- in identifying possible risks that negatively affect the continuity of education in primary and secondary schools: an increase in alternative copyright programs that are not consistent with each other in the subject content; lack of methodological developments, 
taking into account the continuity in the links of education [20]; a uniform approach to the educational achievements of students without taking into account the level of their educational achievements; lack of implementation of end-to-end vertical integration, which determines purposefulness, progressiveness and orderliness, the continuity of personal, meta-subject and subject results of students in the implementation of FGOS PGE and FGOS BGE; inconsistency in the interaction of primary school and primary school in target components, subject content, application of forms, methods and technologies of successive education; overload of teachers; insufficient skills of students to optimally implement the acquired knowledge and skills in practical situations).

The conducted research can serve as a theoretical basis for promising areas of further scientific research: research of the problems of updating the resources of continuity in the self-educational activities of students in the context of lifelong education; development of conceptual foundations of quality management of continuity of education in an educational organization based on profiling.

\section{References}

1. L.A. Alexandrova, About continuity in teaching mathematics between primary and secondary school, Mathematics at school, 1, 16-21 (2013)

2. K.M. Durai-Novikova, Formation of professional readiness of students and pedagogical activity, 16, 48 (Moscow, 1983)

3. A.M. Kondakov, Implementation of the Federal State Educational Standard of the Second Generation, Primary school, 5, 3-5 (2009)

4. O.E. Kurlygina, Competence as a characteristic of the future teacher's readiness to carry out professional activities.- Conf. Modern problems of science and education, $\mathbf{9}$, 34-41 (2014)

5. O. E. Kurlygina, Competence as a characteristic of the future teacher's readiness to carry out professional activities, URL: https://sciencepedagogy.ru/ru/article/view?id=9725 (Scientific review. Pedagogical Sciences, 2015)

6. A.K. Mendygaliyeva, The willingness of the teacher to realization of continuity of education in primary and secondary schools, Problems of modern pedagogical education (cognitive criterion), 10, 11, 13, 14, 15, 17, 125-134 (2016)

7. A.K. Mendygaliyeva, Methodological support of pedagogical measurements of the teacher's readiness to implement the continuity of education in primary schools, Bulletin of the Orenburg state pedagogical University, Electronic scientific journal, 18, 19, 20, 292-301 (2016)

8. A.K. Mendygaliyeva, N.V. Litvinenko, The continuity of mathematical education: formulation and solution of problems, Elementary school, 70-74 (2019)

9. A.K. Markova, Psychology of professionalism, 3, 308 (Moscow, 1996)

10. Pedagogical encyclopedic dictionary 4, p. 528 (Moscow, Bustard: Great Russian Encyclopedia, 2008)

11. Professional standard teacher (pedagogical activity in preschool, primary, general, basic general, secondary general education) (educator, teacher), 544 (approved by order of the Ministry of Labor and Social Protection of the Russian Federation dated October 18, 2013)

12. V.A. Slastenin, Pedagogy, 12, 224 (Moscow: Magister Publishing House, 1997)

13. Dictionary-reference book on pedagogy, 2, p. 448 (Ed. by V.A. Mizherikov; under the general ed. P.N. Pudgy. Moscow.: TC Sphere, 2004) 
14. Yu.G. Tatur, Competence in the structure of the quality model of specialist training, Higher education today, 8, 21-26 (2004)

15. Federal state educational standard in primary general education, 6, Electronic resource, Access mode: http: standart.edu.ru

16. H.W. Heymann, Praxis bildet -aberwie?, 6-10 (Paedagogik. - Weinheim, 2009)

17. V. Kress, NeueWegebei der Ausbildung von Mentorinnen und Mentoren, 30-35 (Paedagogik. - Weinheim, 2009)

18. L. Schmoll, L. Nachbesprechungen von Unterricht, 26-29 (Paedagogik. - Weinheim, 2009) 